\title{
Long non-coding RNA LUCAT1 promotes the progression of clear cell renal cell carcinoma via the microRNA-375/YAP1 axis
}

\author{
XIAOJUN WANG ${ }^{1 *}$, HUI OU $^{1 *}$, LIANGFEN ZHOU $^{2}$, HENGYU LIU $^{1}$, XIAOBAO LIU $^{3}$ and HUIYUN ZHANG ${ }^{1}$ \\ Departments of ${ }^{1}$ Oncology and ${ }^{2}$ Neonatology, Chenzhou No. 1 People's Hospital; ${ }^{3}$ Department of Oncology, \\ The Second People's Hospital of Chenzhou, Chenzhou, Hunan 423000, P.R. China
}

Received September 3, 2019; Accepted December 17, 2020

DOI: $10.3892 /$ etm.2021.10186

\begin{abstract}
Clear cell renal cell carcinoma (ccRCC) is a common renal cell carcinoma with a high mortality rate. Lung cancer-associated transcript 1 (LUCAT1) has been reported to be a potential biomarker of prognosis in human ccRCC. However, the underlying mechanism of the function of LUCAT1 in ccRCC remains poorly understood. The present study aimed to investigate the role and underlying mechanism of LUCAT1 in ccRCC. The expression level of LUCAT1, microRNA-375 (miR-375) and yes-associated protein 1 (YAP1) in ccRCC tissues and cells was detected by reverse transcription-quantitative PCR, and the protein level of YAP1 was detected by western blotting. The effects of LUCAT1 on cell proliferation, migration and invasion were analyzed using Cell Counting Kit-8 and Transwell assays. The association between miR-375 and LUCAT1 or miR-375 and YAP1 was predicted by 1 cBase Predicted v.2 or TargetScan and verified using dual-luciferase reporter assay. The effect of LUCAT1 on ccRCC progression in vivo was evaluated using a xenograft tumor model. The results revealed that LUCAT1 and YAP1 were upregulated and miR-375 was downregulated in ccRCC tissues and cells. LUCAT1 knockdown suppressed cell proliferation, migration and invasion, which were reversed by the inhibition of miR-375. In addition, YAP1 overexpression attenuated the inhibitory effects of miR-375 overexpression on cell proliferation, migration and invasion. Subsequent experiments suggested that LUCAT1 regulated YAP1 expression by sponging miR-375. Therefore, LUCAT1 exerted its role by regulating the miR-375/YAP1 axis in vitro. Moreover, LUCAT1 knockdown suppressed the growth of ccRCC xenograft tumors in vivo. These results collectively revealed that
\end{abstract}

Correspondence to: Dr Huiyun Zhang, Department of Oncology, Chenzhou No. 1 People's Hospital, 8 Qingnian Road, Chenzhou, Hunan 423000, P.R. China

E-mail: zhanggou06814@126.com

*Contributed equally

Key words: clear cell renal cell carcinoma, long non-coding RNA LUCAT1, microRNA-375, yes-associated protein 1
LUCAT1 promoted the proliferation, migration and invasion of ccRCC by the upregulation of YAP1 via sponging miR-375, which may be used as a potential therapeutic target for ccRCC.

\section{Introduction}

Renal cell carcinoma (RCC) accounts for $5 \%$ of all adult malignancies with 300,000 new cases and 100,000 deaths per year worldwide (1). Clear cell RCC (ccRCC) is the most common subtype of renal cancer, which accounts for $75 \%$ of RCC worldwide (2). ccRCC is resistant to chemotherapy and radiotherapy, therefore its clinical management has become a difficult issue (3). Although the diagnosis, treatment and overall survival rate of patients with ccRCC have been markedly improved in recent years, long-term prognosis is still limited and $30 \%$ of patients experience recurrence of renal cancer $(4,5)$. Therefore, further studies are required to clarify the underlying mechanism of ccRCC progression and develop efficient therapeutic targets for ccRCC.

Long non-coding RNAs (lncRNAs) are non-coding RNAs with $>200$ nucleotides, and have been indicated to exert critical roles in various cellular and biological processes (6). Accumulating evidence has suggested that lncRNAs function as tumor suppressors or oncogenes in diverse tumors, including ccRCC. Liu et al (7) demonstrated that knockdown of lncRNA TP73-AS1 inhibited cell proliferation and invasion, and induced cell apoptosis by binding to KISS1 in ccRCC. Hirata et al (8) reported that lncRNA MALAT1 served as an oncogene by promoting proliferation and suppressing apoptosis in ccRCC. Lung cancer-associated transcript 1 (LUCAT1) has also been demonstrated to serve a vital role in ccRCC progression. For instance, a previous study has reported that LUCAT1 served as a poor prognostic factor in human ccRCC (9). Moreover, it has been demonstrated that LUCAT1 overexpression induced cell proliferation and invasion via the AKT/GSK-3 $\beta$ signaling pathway, indicating that LUCAT1 may be used as a potential therapeutic target in ccRCC (10). Additionally, LUCAT1 has been revealed to function as an oncogene via regulating the microRNA (miRNA/miR)-495-3p/SATB1 axis, thereby promoting cell proliferation and invasion in ccRCC (11). However, the molecular mechanism underlying the biological function of LUCAT1 in ccRCC remains to be fully elucidated. miRNAs are non-coding RNAs with 19-22 nucleotides in length, which serve as important regulators of gene expression 
via binding to the 3'-untranslated region (3'-UTR) of target mRNAs (12). Accumulating evidence has indicated that abnormal expression of miRNAs, functioning as oncogenes or tumor suppressors, was associated with the progression and development of cancer, including ccRCC (13). Several studies have demonstrated that miR-375 was downregulated in several types of cancer, such as gastric cancer (14), glioma (15) and cervical cancer (16). In renal cancer, miR-375 has been reported to act as a tumor suppressor via inhibiting cell proliferation, migration and invasion (17). Therefore, the aforementioned studies have indicated the pivotal role of miR-375 in different types of cancer, especially in ccRCC, while few studies have examined the network of molecules upstream and downstream of miR-375 in ccRCC.

Yes-associated protein 1 (YAP1), which is a transcriptional co-activator, has also been associated with the development of ccRCC. YAP1 has been demonstrated to serve an oncogenic role in various types of cancer, including ccRCC (18). Upregulation of YAP1 has been revealed to accelerate cell growth, migration, invasion and epithelial-mesenchymal transition via modulating arrestin domain-containing protein 1/3 (19), suggesting that YAP1 may participate in ccRCC development.

The present study aimed to investigate the role and underlying mechanism of LUCAT1 in ccRCC in vitro and in vivo.

\section{Materials and methods}

Clinical specimens and cell culture. ccRCC tissues $(\mathrm{n}=62)$ and paired adjacent healthy tissues $(n=62)$ were obtained from patients with ccRCC who were hospitalized at Chenzhou No. 1 People's Hospital (Chenzhou, China) between May 2016 and March 2018. The patient age range was 34-79 years, with a median age of 65 years, and 29 patients were females and 33 were males. The inclusion criteria included a clinical and imaging diagnosis of primary non-metastatic ccRCC. The exclusion criteria included patients with active malignancy other than RCC, cardiovascular disease, blood disease or other malignant tumor types. The present study was approved by the Ethics Committee of Chenzhou No. 1 People's Hospital and all participants provided written informed consent.

A normal human proximal tubular epithelial cell line (HK-2) and RCC cell lines (786-O, Caki-1, A498, 769-P and ACHN) were obtained from American Type Culture Collection. All RCC cell lines were cultured in RPMI-1640 (Invitrogen; Thermo Fisher Scientific, Inc.) supplemented with 10\% FBS (Gibco; Thermo Fisher Scientific, Inc.) and 1\% penicillin/streptomycin (5,000 U/ml, Gibco; Thermo Fisher Scientific, Inc.). HK-2 cells were cultured in DMEM supplemented with 10\% FBS (both from Gibco; Thermo Fisher Scientific, Inc.) and $1 \%$ penicillin/streptomycin. $293 \mathrm{~T}$ cells were purchased from The Cell Bank of Type Culture Collection of the Chinese Academy of Sciences. 293T cells were cultured in DMEM supplemented with $10 \%$ FBS and $1 \%$ penicillin/streptomycin. The cells were maintained at $37^{\circ} \mathrm{C}$ in a humidified incubator with $5 \% \mathrm{CO}_{2}$.

Cell transfection. LUCAT1 overexpression vector was constructed by cloning full-length LUCAT1 into pcDNA3.1 (Invitrogen; Thermo Fisher Scientific, Inc.), and the empty vector pcDNA3.1 was used as the negative control. Small interfering (si)-RNAs targeting LUCAT1 (si-LUCAT1\#1 and \#2; final concentration, $20 \mathrm{nM}$ ) and its scrambled negative control (NC) siRNA (si-NC; final concentration, $20 \mathrm{nM}$ ), miR-375 inhibitor (final concentration, $30 \mathrm{nM}$ ) and control (miR-NC; final concentration, $30 \mathrm{nM}$ ) and miR-375 mimics (final concentration, $15 \mathrm{nM}$ ) and control (miR-NC mimics; final concentration, $15 \mathrm{nM}$ ) were obtained from Shanghai GenePharma Co., Ltd. 1x10 ${ }^{6}$ Caki-1 and A498 cells were plated into six-well plates for $12 \mathrm{~h}$, then the constructs were transfected into Caki-1 and A498 cells by mixing with Lipofectamine ${ }^{\circledR} 2000$ reagent (Invitrogen; Thermo Fisher Scientific, Inc.) at $37^{\circ} \mathrm{C}$ for $15 \mathrm{~min}$ following the manufacturer's instructions. A total of 24-72 $\mathrm{h}$ after transfection, the transfected cells were collected for subsequent experiments. The sequences of the transfected molecules were as follows: si-LUCAT1\#1, 5'-CCCAUCAGAAGAUGUCAGAAGAUA A-3'; si-LUCAT1\#2, 5'-UGUCCCUCAGUGUUCUACUUC UUAA-3'; si-NC, 5'-AAUUCUCCGAACGUGUCACGU-3'; miR-375 inhibitor, 5'-UCACGCGAGCCGAACGAACAA A-3'; anti-miR-NC, 5'-CAGUACUUUUGUGUAGUACAA A-3'; miR-375 mimic, 5'-UUUGUUCGUUCGGCUCGC GUGA-3'; miR-NC, 5'-GGUUCGUACGUACACUGUUCA-3'.

Reverse transcription-quantitative PCR (RT-qPCR). Total RNA was extracted from cells (786-O, Caki-1, A498, 769-P, ACHN and HK-2) and ccRCC tissues using TRIzol ${ }^{\circledR}$ reagent (Invitrogen; Thermo Fisher Scientific, Inc.) and cDNA synthesis was performed using Maxima Probe qPCR Master mix (Fermentas; Thermo Fisher Scientific, Inc.) according to the manufacturer's instructions. Quantitative analysis of LUCAT1 and YAP1 expression was performed using SYBR $^{\circledR}$ Premix Ex Taq ${ }^{\mathrm{TM}}$ reagent (Takara Biotechnology Co., Ltd.) and GAPDH was used as the endogenous control. Thermocycling conditions were as follows: $94^{\circ} \mathrm{C}$ for $3 \mathrm{~min}$; 40 cycles of $94^{\circ} \mathrm{C}$ for $30 \mathrm{sec}, 55^{\circ} \mathrm{C}$ for $30 \mathrm{sec}$ and $72^{\circ} \mathrm{C}$ for $1 \mathrm{~min}$; and $72^{\circ} \mathrm{C}$ for $10 \mathrm{~min}$. The expression level of miR-375 was analyzed using SYBR PrimeScript ${ }^{\mathrm{TM}}$ miRNA RT-PCR kit (Takara Biotechnology Co., Ltd.) and U6 small nuclear RNA was used as the internal reference. Thermocycling conditions were as follows: Denaturation at $95^{\circ} \mathrm{C}$ for $10 \mathrm{sec} ; 40$ cycles of $95^{\circ} \mathrm{C}$ for $5 \mathrm{sec}$ and $60^{\circ} \mathrm{C}$ for $20 \mathrm{sec}$; followed by dissociation curve analysis at $95^{\circ} \mathrm{C}$ for $60 \mathrm{sec}, 55^{\circ} \mathrm{C}$ for $30 \mathrm{sec}$ and $95^{\circ} \mathrm{C}$ for $30 \mathrm{sec}$. Relative expression levels were calculated using the $2^{-\Delta \Delta \mathrm{Cq}}$ method (20). Primer sequences were listed as follows: LUCAT1 forward, 5'-GTGTCAAGCTCGGATTGCCT-3' and reverse, 5'-GAGCCCACACACTCAG-3'; GAPDH forward, 5'-AGAAGGCTGGGGCTCATTTG-3' and reverse, 5'-AGG GGCCATCCACAGTCTTC-3'; YAP1 forward, 5'-TGACCC TCGTTTTGCCATGA-3' and reverse, 5'-GTTGCTGCTGGT TGGAGTTG-3'; miR-375 forward, 5'-GTGCAGGGTCCG AGGT-3' and reverse, 5'-AGCCGTTTGTTCGTTCGGCT-3'; U6 forward, 5'-CTCGCTTCGGCAGCACA-3' and reverse, 5'-AACGCTTCACGAATTTGCGT-3'.

Pathological analysis. In brief, the ccRCC tissues and paired adjacent healthy tissues were processed according to standard procedures, including $10 \%$ formalin fixation for $5 \mathrm{~min}$ at room temperature, dehydration in graded alcohol series $(30,50,70$, 95 and twice $100 \%$ alcohol) and xylene and embedding in 
paraffin. Subsequently, the tissue biopsies ( $3 \mu \mathrm{m})$ were stained with hematoxylin for $5 \mathrm{~min}$ and eosin for another $2 \mathrm{~min}$ at room temperature (Abcam). Finally, the tissues were observed under a light microscope at x200 magnification and photographed.

Dual-luciferase reporter assay. The binding sites between miR-375 and LUCAT1, as well as miR-375 and YAP were predicted by lncBase Predicted v.2 (http://www.microrna. $\mathrm{gr} / \mathrm{lncBase}$ ) or TargetScan software (http://www.targetscan. org/vert_50/), respectively. LUCAT1 and YAP1 3'-UTR containing the wild-type (WT) or mutant (MUT) binding sites of miR-375 was synthesized and cloned into pmirGLO luciferase reporter vector (Promega Corporation). Subsequently, $1 \times 10^{6} 293 \mathrm{~T}$ cells were plated into six-well plates for $12 \mathrm{~h}$, then LUCAT1-WT, LUCAT1-MUT, YAP1-WT or YAP1-MUT were co-transfected with miR-375 mimics or miR-NC into 293T cells using Lipofectamine 2000 reagent (Invitrogen; Thermo Fisher Scientific, Inc.). A total of $48 \mathrm{~h}$ following transfection, the Renilla and firefly luciferase activity was measured using Luc-Pair ${ }^{\mathrm{TM}}$ Duo-Luciferase Assay kit (Shanghai Yeasen Biotechnology Co., Ltd.) according to the manufacturer's instructions. Renilla luciferase activity was used for normalization.

Western blotting. Total protein was extracted from Caki-1 and A498 cells using a Cell lysis buffer for Western and IP (Beyotime Institute of Biotechnology) following the manufacturer's protocol. The protein samples were quantified using a BCA Protein Assay Kit (Beyotime Institute of Biotechnology). A total of $30 \mu \mathrm{g}$ protein/sample were separated by $10 \%$ SDS-PAGE, and subsequently transferred onto a nitrocellulose membrane (MilliporeSigma). The membrane was blocked with 5\% skimmed milk in TBS-Tween-20 (0.1\%) buffer for $1 \mathrm{~h}$ at room temperature. Subsequently, the membrane was incubated with primary antibodies against YAP1 (1:600; cat. no. ab52771) and GAPDH (1:4,000; cat. no. ab8245) (both from Abcam) overnight at $4^{\circ} \mathrm{C}$. Subsequently, the membranes were incubated with HRP-conjugated goat anti-rabbit $\mathrm{IgG}$ H\&L secondary antibody (1:20,000; cat. no. ab6721; Abcam) for $1 \mathrm{~h}$ at room temperature. Finally, the protein bands were visualized with an ECL kit (GE Healthcare) and analyzed using ImageJ v1.8.0 software (National Institutes of Health).

Cell viability assay. A total of $2 \times 10^{3}$ Caki- 1 and A498 cells were seeded in a 96-well plate. After incubation for 24, 48 and $72 \mathrm{~h}, 10 \mu 1$ CCK-8 solution (Beyotime Institute of Biotechnology) was added to each well and incubated at $37^{\circ} \mathrm{C}$ for $4 \mathrm{~h}$ according to the manufacturer's protocol. Subsequently, the absorbance at $450 \mathrm{~nm}$ was determined using an Elx800 Absorbance Microplate Reader (BioTek Instruments, Inc.).

Cell migration and invasion assay. Transwell chambers (12-well; MilliporeSigma) were used to assess the migratory and invasive abilities of Caki-1 and A498 cells. In brief, $1 \times 10^{5}$ cells were seeded into the upper chamber for the migration assay, while $2 \times 10^{5}$ cells were plated into the upper chamber, which was pre-coated with $50 \mu \mathrm{l}$ Matrigel at $37^{\circ} \mathrm{C}$ for $30 \mathrm{~min}$ (BD Biosciences), for the invasion assay. The cells were seeded in the upper chambers in serum-free RPMI-1640 medium, while RPMI-1640 supplemented with 10\% FBS was placed into the lower chamber. Following incubation for $24 \mathrm{~h}$ at $37^{\circ} \mathrm{C}$, the migrated/invaded cells were fixed with $100 \%$ methanol for $30 \mathrm{~min}$ and stained with $0.05 \%$ crystal violet for $20 \mathrm{~min}$ at room temperature. Finally, the cells were photographed using an inverted microscope at $\mathrm{x} 400$ magnification, and the average number of migrated or invaded cells in five random microscopic fields per Transwell was manually counted.

Tumor xenografts. The present study was approved by the Animal Ethics Committee of Chenzhou No. 1 People's Hospital (Chenzhou, China). Lentiviral-based short hairpin (sh)-LUCAT1 vector and lentiviral empty vector (sh-NC) were obtained from Shanghai GeneChem Co., Ltd. The sequences of sh-LUCAT1 or sh-NC were cloned and inserted into hU6-MCS-Ubiquitin-EGFP-IRES-puromycin lentiviral vector (Shanghai GeneChem Co., Ltd.) to construct the recombinant lentiviral vector. $5 \times 10^{6} 293 \mathrm{~T}$ cells at the exponential growth phase were plated into $100 \mathrm{~mm}$ cell culture plates for $12 \mathrm{~h}$, then the recombinant lentiviral vectors $(16 \mu \mathrm{g})$ and $20 \mu \mathrm{l}$ Lenti-Easy Packaging Mix (Shanghai GeneChem Co., Ltd.) were co-transfected into $293 \mathrm{~T}$ cells using Lipofectamine 2000 for $48 \mathrm{~h}$ at $37^{\circ} \mathrm{C}$. A total of $48 \mathrm{~h}$ after transfection, the cell supernatants were collected and filtered using a $0.22 \mu \mathrm{M}$ polyethersulfone membrane filter. The supernatants were then centrifuged at $8,000 \times \mathrm{g}$ for $10 \mathrm{~min}$ at $4^{\circ} \mathrm{C}$ to collect the lentiviral particles. Subsequently, the titers were determined by fluorescent microscopy. The titer was approximately $4-10 \times 10^{8}$ infectious units $/ \mathrm{ml}$. To establish the stable LUCAT1 knockdown cell line, $1 \times 10^{6}$ Caki-1 cells were cultured in a six-well plate with culture media containing lentivirus at $50 \mathrm{MOI}$ for $72 \mathrm{~h}$. A total of 3 days after infection, the cells were incubated with $2 \mu \mathrm{g} / \mathrm{ml}$ puromycin for 2 weeks to select the stably transfected cells.

Five-week-old male BALB/c nude mice with an average body weight of $\sim 20 \mathrm{~g}$ were provided by the Animal Center of Nanjing University (Nanjing, China), and were divided into two groups ( 6 mice in total; $n=3$ per group). All introduced mice were bio-purified and were entered into the animal facility after veterinary authorization. The mice were housed in a pathogen-free environment at $25^{\circ} \mathrm{C}, 45-50 \%$ humidity and a programmed $12 \mathrm{~h}$ light/ $12 \mathrm{~h}$ dark cycle. All mice were allowed free access to drinking water and a sterilized standard diet. Any effort was made to avoid unnecessary pain of the animals. Stably transfected Caki- 1 cells $\left(3 \times 10^{6}\right.$ cells in $100 \mu 1$ PBS) were subcutaneously injected into the left flank of the nude mice. The volume of the tumors was measured every 6 days after 6 days of injection. A total of 30 days after injection, the mice were sacrificed by cervical dislocation after deep anesthesia with 2\% isoflurane (Baxter International Inc.), and the tumors were excised and weighed. The level of LUCAT1 in the excised tumors was detected by RT-qPCR. Additionally, the humane endpoint criteria used in the present study were as follows: During the post-operative period, the mice were inspected daily to ensure their ability to eat, drink and ambulate normally; when they exhibited apparent physical defects, such as dry or dull eyes, sticky mucous membranes, ambulation difficulties, dyspnea or cachexia (loss of $15 \%$ of animal original body weight), the mice were deemed to meet the criteria of euthanasia and were sacrificed to minimize suffering and distress. 

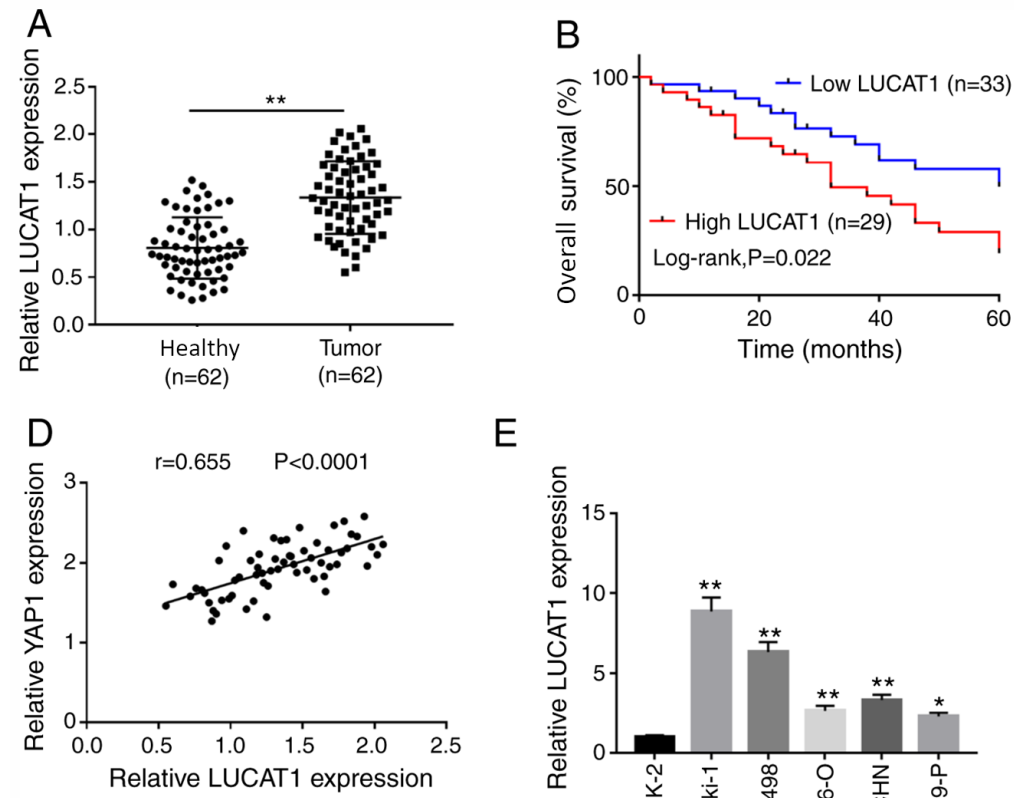

$\mathrm{E}$
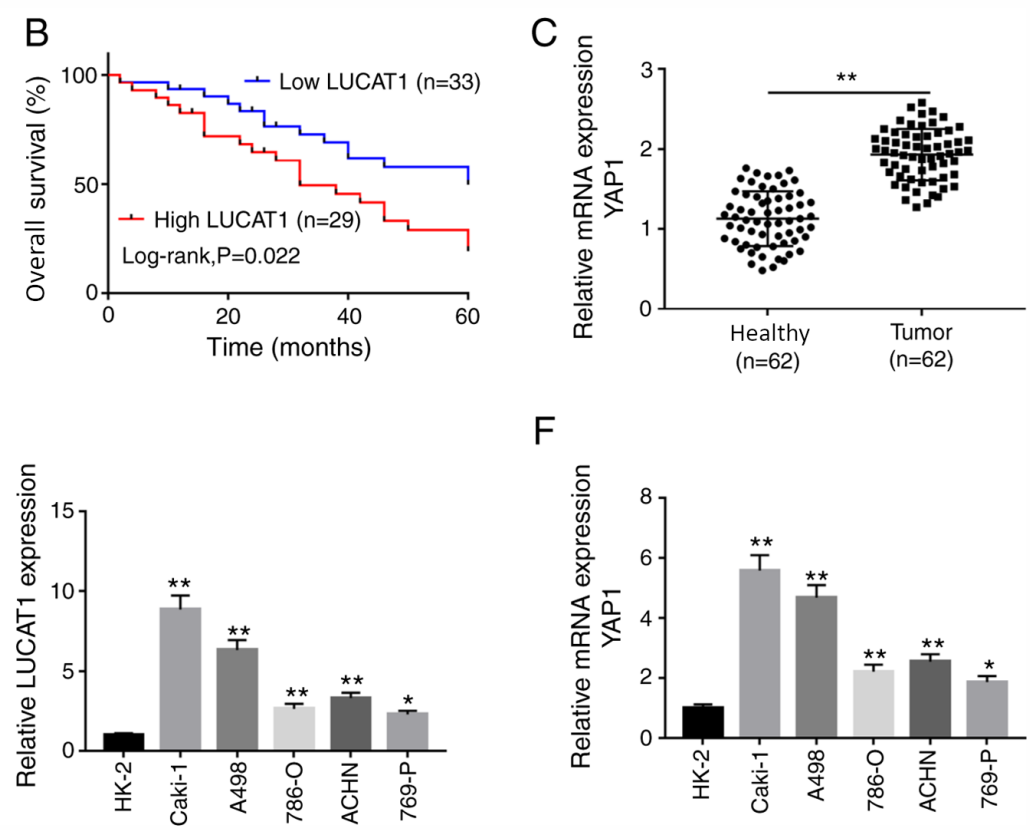

$\mathrm{F}$

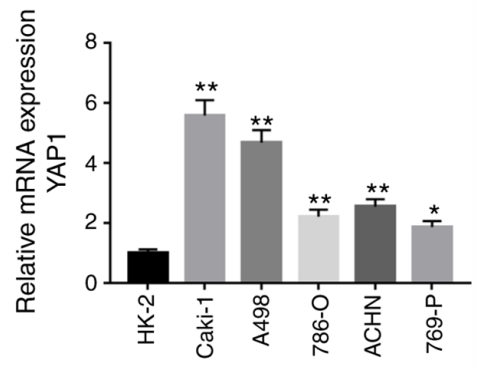

Figure 1. Expression of LUCAT1 and YAP1 in ccRCC tissues and cells. (A) The expression of LUCAT1 in 62 pairs of ccRCC tissues and adjacent healthy tissues was detected by RT-qPCR. (B) The association between the expression level of LUCAT1 and the overall survival in patients with ccRCC was determined by Kaplan-Meier analysis. (C) The expression of YAP1 in 62 pairs of ccRCC tissues and adjacent healthy tissues was detected by RT-qPCR. (D) The correlation between LUCAT1 and YAP1 expression level in ccRCC tissues was assessed using Pearson's correlation analysis. The expression level of (E) LUCAT1 and (F) YAP1 in the normal human proximal tubular epithelial cell line HK-2 and RCC cell lines (786-O, Caki-1, A498, 769-P and ACHN) was determined by RT-qPCR. ${ }^{*} \mathrm{P}<0.05$ and ${ }^{* *} \mathrm{P}<0.01$ vs. healthy tissues or normal cells. RT-qPCR, reverse transcription-quantitative PCR; LUCAT1, lung cancer-associated transcript 1; YAP1, yes-associated protein 1; ccRCC, clear cell renal cell carcinoma.

Statistical analysis. Statistical analysis was performed using SPSS v20.0 software (IBM Corp.). All experiments were analyzed in triplicate and are presented as the mean \pm SD. Pearson's correlation was used to assess the correlation between LUCAT1 and miR-375, as well as miR-375 and YAP1. Comparisons between two groups were performed using paired or unpaired Student's t-test, while comparisons among $\geq 3$ groups were performed using one-way ANOVA followed by Tukey's post hoc test. Pearson's $\chi^{2}$ test or Fisher's exact test were used to assess categorical variables. $\mathrm{P}<0.05$ was considered to indicate a statistically significant difference.

\section{Results}

LUCATI and YAPl expression levels are increased in ccRCC tissues and cells. LUCAT1 and YAP1 mRNA expression levels were significantly increased in ccRCC tissues, compared with the adjacent healthy tissues (Fig. 1A and C). Similarly, LUCAT1 and YAP1 mRNA expression levels were upregulated in ccRCC cell lines (786-O, Caki-1, A498, 769-P and ACHN) compared with the human normal proximal tubular epithelial cell line HK-2 (Fig. 1E and F). Pearson's correlation analysis demonstrated that the expression of LUCAT1 was positively correlated to that of YAP1 in ccRCC tissues (Fig. 1D). To explore whether the expression of LUCAT1 was associated with prognosis, patients with ccRCC were divided in low $(n=33)$ and high LUCAT1 group $(n=29)$ according to the median expression of LUCAT1. The results revealed that the low LUCAT1 group exhibited a higher overall survival rate compared with the high LUCAT1 group (Fig. 1B), suggesting a close association between LUCAT1 expression level and prognosis. To further assess the role of LUCAT1 in the prognosis of ccRCC, patients were divided into two groups (high and low expression) based on the median expression levels of LUCAT1, and the association between LUCAT1 expression and clinicopathological factors of patients with ccRCC was analyzed. The clinicopathological characteristics of all 62 patients are presented in Table I. Statistical analysis indicated that LUCAT1 expression was associated with the tumor stage, tumor size and lymph node metastasis of ccRCC. In addition, a significant association was observed between YAP1 expression level (low and high YAP1 expression level was divided based on the mean value of YAP1 expression level) and tumor stage, tumor size or lymph node metastasis in patients with ccRCC (Table SI). Furthermore, H\&E staining of the adjacent healthy kidney group and ccRCC tissues is presented in Fig. S1. Compared with the adjacent healthy kidney group, the tumors displayed dense cellularity with brightly eosinophilic cytoplasm, and were arranged in nests. These results indicated that LUCAT1 and YAP1 were associated with ccRCC progression.

LUCAT1 directly targets miR-375 in RCC cells. Increasing evidence has suggested that IncRNAs act as molecular sponges or competing endogenous RNAs (ceRNAs), regulating miRNA expression, thereby affecting their biological function (21). Using the bioinformatics tool lncBase Predicted v.2, LUCAT1 was predicted to contain complementary bases to miR-375 (Fig. 2A). Transfection of miR-375 mimics decreased the luciferase activity of the LUCAT1-WT group compared with the miR-NC mimics transfection (Fig. 2B), while there was little change in the luciferase activity of 
Table I. Association of clinicopathological features with LUCAT1 expression in patients with clear cell renal cell carcinoma.

\begin{tabular}{|c|c|c|c|c|}
\hline \multirow[b]{2}{*}{ Parameter } & \multirow[b]{2}{*}{ Number of cases } & \multicolumn{2}{|c|}{ LUCAT1 expression } & \multirow[b]{2}{*}{ P-value } \\
\hline & & Low $(n=33)$ & High $(\mathrm{n}=29)$ & \\
\hline \multicolumn{5}{|l|}{ Sex } \\
\hline Female & 30 & 16 & 14 & 0.124 \\
\hline Male & 32 & 17 & 15 & \\
\hline \multicolumn{5}{|l|}{ Age, years } \\
\hline$\leq 55$ & 27 & 15 & 12 & 0.074 \\
\hline$>55$ & 35 & 18 & 17 & \\
\hline \multicolumn{5}{|c|}{ Tumor stage } \\
\hline $\mathrm{T} 1-2$ & 40 & 27 & 13 & $0.003^{\mathrm{b}}$ \\
\hline T3-4 & 22 & 6 & 16 & \\
\hline \multicolumn{5}{|l|}{ Tumor size } \\
\hline$\leq 4 \mathrm{~cm}$ & 28 & 20 & 8 & $0.005^{\mathrm{b}}$ \\
\hline$>4 \mathrm{~cm}$ & 34 & 13 & 21 & \\
\hline \multicolumn{5}{|c|}{ Lymph node metastasis } \\
\hline No & 36 & 22 & 14 & $0.011^{\mathrm{b}}$ \\
\hline Yes & 26 & 11 & 15 & \\
\hline \multicolumn{5}{|c|}{ Distant metastasis } \\
\hline No & 39 & 21 & 18 & 0.086 \\
\hline Yes & 23 & 12 & 11 & \\
\hline
\end{tabular}

aPearson's $\chi^{2}$ test was used. ${ }^{\mathrm{b}} \mathrm{P}<0.05$ was considered to indicate a statistically significant difference. $\mathrm{T}$, tumor; LUCAT1, lung cancer-associated transcript 1 .

the LUCAT1-MUT group, indicating that LUCAT1 directly targeted miR-375. A negative correlation was also observed between miR-375 and LUCAT1 expression level in ccRCC tissues (Fig. 2D). In addition, the results indicated that the expression level of miR-375 was decreased in ccRCC tissues and cell lines compared with healthy tissues and normal cells, respectively (Fig. 2C and E). Moreover, based on the higher or lower than the median expression levels of miR-375, the patients were divided into two groups, and the association between miR-375 expression and clinicopathological factors of patients with ccRCC was analyzed. Our results indicated that the expression level of miR-375 was associated with tumor stage, tumor size, lymph node metastasis and distant metastasis in patients with ccRCC (Table SII). Furthermore, LUCAT1 was upregulated, while miR-375 was downregulated in LUCAT1-overexpressing Caki-1 and A498 cells compared with the vector-NC group (Fig. $2 \mathrm{~F}$ and $\mathrm{H}$ ). In Caki-1 and A498 cells transfected with si-LUCAT1\#1 or si-LUCAT1\#2, LUCAT1 expression level was decreased, while miR-375 expression level was increased compared with the si-NC group (Fig. 2G and I). These results indicated that LUCAT1 interacted with miR-375.

LUCAT1 knockdown inhibits cell proliferation, migration and invasion via regulating miR-375 in $R C C$ cells. To explore the effects of LUCAT1 and miR-375 in ccRCC cells, in vitro assays were performed. The transfection efficiency of miR-375 mimics and inhibitor compared with their respective
NCs in Caki-1 and A498 cells was examined via RT-qPCR (Fig. S2A and B). Caki-1 and A498 cells were transfected with si-NC, si-LUCAT1\#1, si-LUCAT1\#1 + miR-NC or si-LUCAT1\#1 + miR-375 inhibitor. RT-qPCR analysis indicated that miR-375 expression was increased in Caki-1 and A498 cells transfected with si-LUCAT1\#1, but was inhibited by miR-375 inhibitor (Fig. 3A). Subsequently, CCK-8 and Transwell assays were performed to examine the role of LUCAT1 and miR-375 in ccRCC progression. As demonstrated in Fig. 3B and C, LUCAT1 knockdown inhibited the proliferation of Caki-1 and A498 cells, which was reversed by miR-375 inhibition. Transwell assay revealed that LUCAT1 silencing significantly inhibited the migratory and invasive abilities of Caki-1 and A498 cells, while miR-375 inhibitor inverted the si-LUCAT1\#1-induced inhibitory effects on cell migration and invasion of Caki-1 and A498 cells (Fig. 3D and E). Furthermore, the results of the present study also suggested that the overexpression of LUCAT1 promoted the proliferation, migration and invasion of Caki-1 and A498 cells (Fig. S3). Together, these results demonstrated that LUCAT1 regulated cell proliferation, migration and invasion via targeting miR-375 in RCC cells.

YAPl is a target of miR-375 in RCC cells. Previous studies have reported that miRNAs exert their function by targeting the 3'-UTR of mRNAs $(11,12)$. The TargetScan software indicated the existence of binding sites between miR-375 and YAP1 (Fig. 4A). To further validate this prediction, YAP1-WT 
A
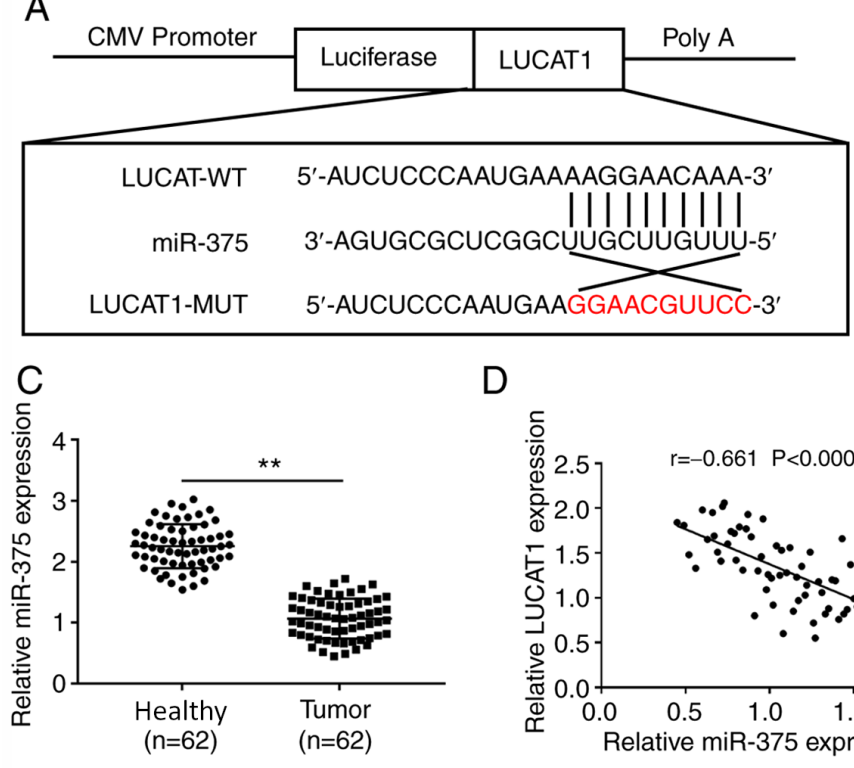

$\mathrm{F}$

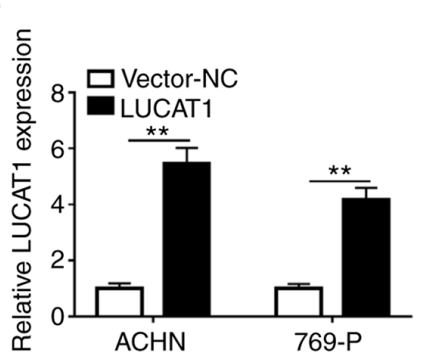

$\mathrm{H}$

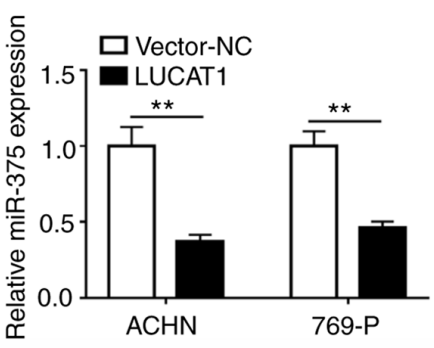

G

I
$\mathrm{B}$

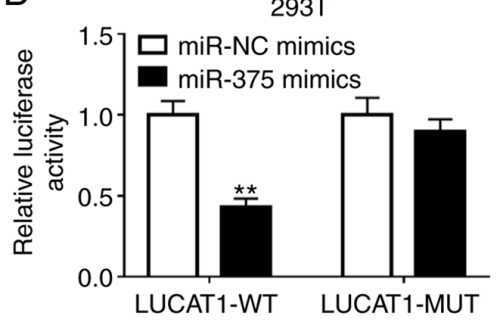

$\mathrm{E}$

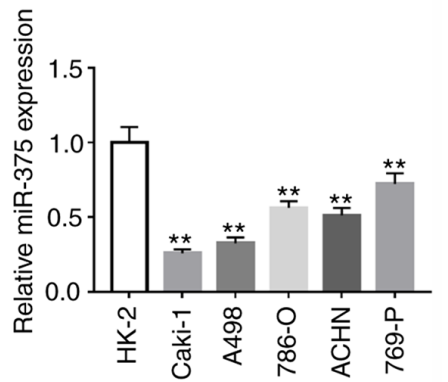

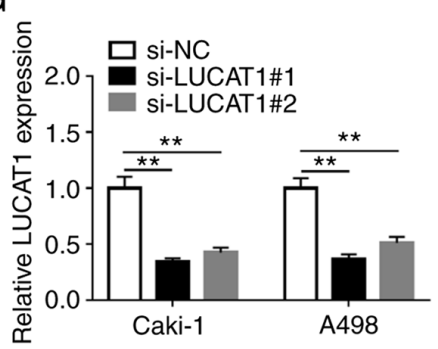

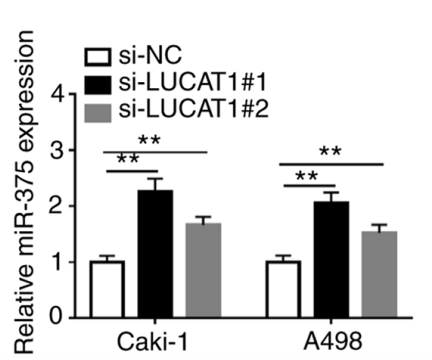

Figure 2. LUCAT1 directly binds to miR-375. (A) The binding sites between LUCAT1 and miR-375 were predicted using the lncBase Predicted v.2 software. (B) The effects of miR-375 overexpression on the luciferase activity of LUCAT1-WT or LUCAT1-MUT reporter were detected using a dual-luciferase reporter assay. (C) miR-375 expression in 62 pairs of ccRCC tissues and adjacent healthy tissues was measured by RT-qPCR. (D) The correlation between LUCAT1 and miR-375 expression levels in ccRCC tissues was analyzed by Pearson's correlation analysis. (E) miR-375 expression in the normal human proximal tubular epithelial cell line HK-2 and RCC cell lines (786-O, Caki-1, A498, 769-P and ACHN) was measured by RT-qPCR. (F) Overexpression or (G) knockdown efficiency of LUCAT1 was determined by RT-qPCR in ACHN and 769-P cells or Caki-1 and A498 cells, respectively. The effects of LUCAT1 (H) overexpression or (I) knockdown on miR-375 level in ACHN and 769-P cells or Caki-1 and A498 cells, respectively, were measured by RT-qPCR. ${ }^{* *} \mathrm{P}<0.01$ vs. the indicated groups or HK-2 cells. RT-qPCR, reverse transcription-quantitative PCR; LUCAT1, lung cancer-associated transcript 1; RCC, renal cell carcinoma; ccRCC, clear cell RCC; miR, microRNA; WT, wild-type; MUT, mutant; si, small interfering; NC, negative control.

or YAP1-MUT reporter plasmids and miR-NC or miR-375 mimics were co-transfected into 293T cells. The luciferase activity of the YAP1-WT reporter was suppressed in cells transfected with miR-375 mimics, while a small alteration was observed in the luciferase activity of the YAP1-MUT group compared with that of the miR-NC group (Fig. 4B). Moreover, the expression level of miR-375 was negatively correlated with that of YAP1 in ccRCC tissues (Fig. 4C). Subsequent western blot assays confirmed that overexpression of miR-375 reduced the protein level of YAP1, while the protein level of YAP1 was increased by miR-375 knockdown in Caki-1 and A498 cells (Fig. 4D and E). These results indicated that miR-375 directly targeted YAP1 and inhibited the transcription and translation of YAP1 in RCC cells.

miR-375 suppresses cell proliferation, migration and invasion by targeting YAPl in RCC cells. To further investigate whether miR-375 exerted its function by targeting YAP1 in RCC, Caki-1 and A498 cells were transfected with miR-NC, miR-375 mimics, miR-375 mimics+vector or miR-375 mimics+YAP1. The transfection efficiency of the YAP1 overexpressing vector in Caki-1 and A498 cells compared with its respective NC is presented in Fig. S2C and D. As depicted in Fig. 5A and B, the level of YAP1 mRNA was significantly 
A

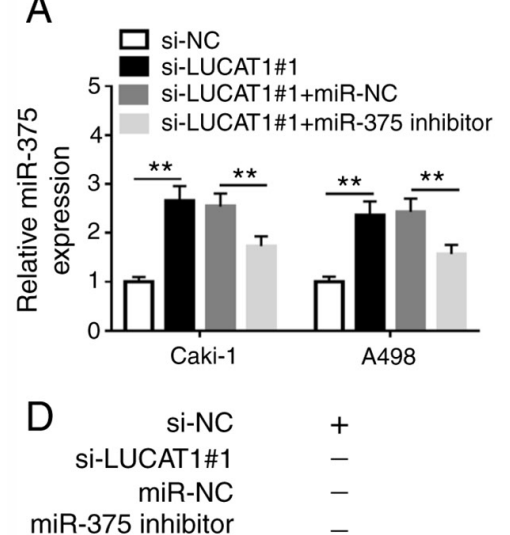

B

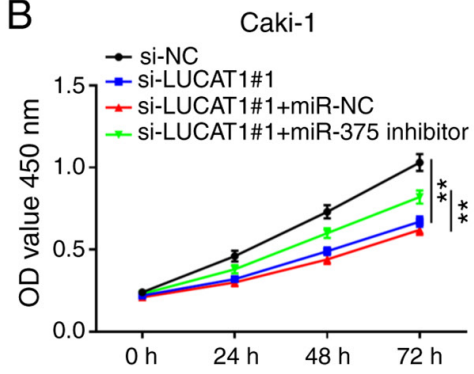

C

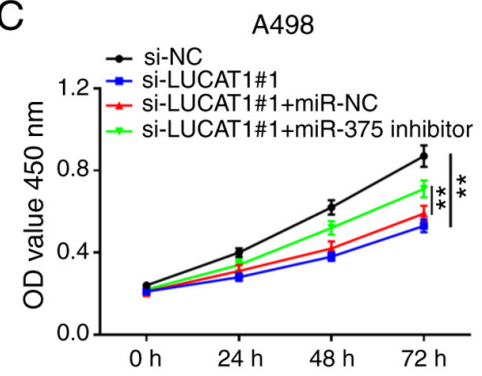

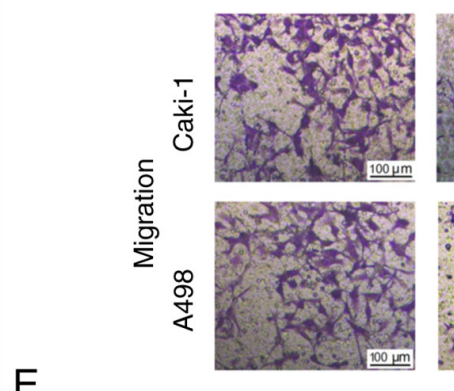
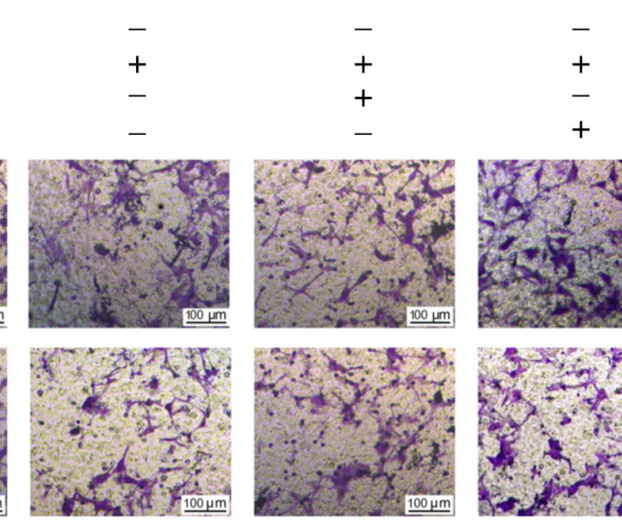

-
+
-
-

-
+
+
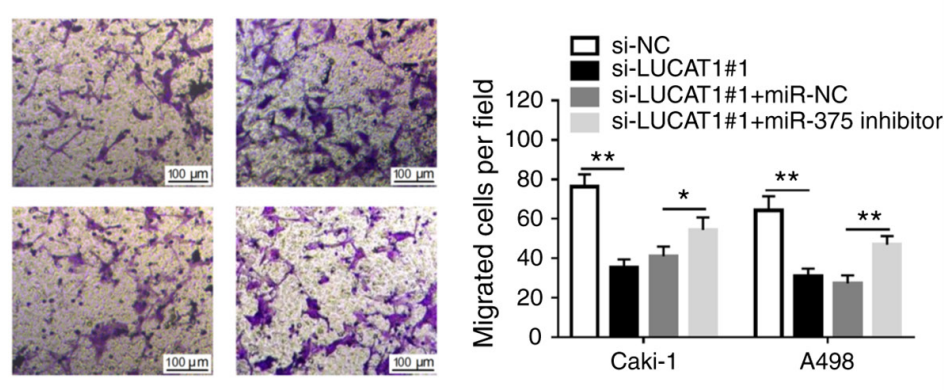

E $\begin{array}{rc}\text { si-NC } & + \\ \text { Si-LUCAT1\#1 } & - \\ \text { miR-NC } & - \\ \text { R-375 inhibitor } & -\end{array}$
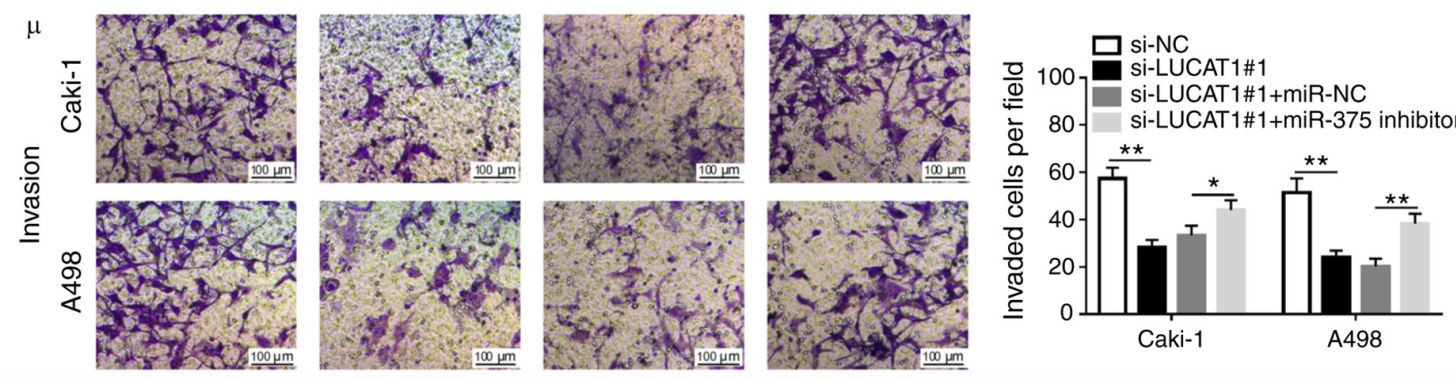

Figure 3. LUCAT1 knockdown suppresses the proliferation, migration and invasion of renal cell carcinoma cells by regulating miR-375 in vitro. (A) The expression level of miR-375 was measured by reverse transcription-quantitative PCR in Caki-1 and A498 cells transfected with si-NC, si-LUCAT1\#1, si-LUCAT1\#1+miR-NC or si-LUCAT1\#1+miR-375 inhibitor. Cell proliferation was examined using the Cell Counting Kit-8 assay in transfected (B) Caki-1 and (C) A498 cells. (D) Cell migratory and (E) invasive capabilities were assessed by Transwell assay in transfected Caki-1 and A498 cells. "P<0.05 and ${ }^{* *} \mathrm{P}<0.01$. LUCAT1, lung cancer-associated transcript 1; miR, microRNA; si, small interfering; NC, negative control; OD, optical density.

decreased in miR-375-overexpressing Caki-1 and A498 cells, which was partially reversed by the overexpression of YAP1. Overexpression of miR-375 decreased the protein level of YAP1, while this decrease was abolished by YAP1 overexpression (Fig. 5C and D). Furthermore, miR-375 overexpression promoted cell proliferation, migration and invasion in Caki-1 and A498 cells, while these effects were reversed by YAP1 overexpression (Fig. 5E-H). These data suggested that miR-375 suppressed RCC phenotypes via targeting YAP1.

Knockdown of LUCAT1 suppresses cell proliferation, migration and invasion by regulating the miR-375/YAPI axis in RCC cells. As aforementioned, the present study hypothesized that LUCAT1 exerted its carcinogenic role via the LUCAT1/miR-375/YAP1 regulatory axis. RT-qPCR results demonstrated that knockdown of LUCAT1 decreased the mRNA level of YAP1, which was abolished by miR-375 inhibition in RCC cells (Fig. 6A). Western blotting results confirmed that miR-375 inhibitor reversed the si-LUCAT1-mediated inhibitory effect on YAP1 protein expression level in Caki-1 and A498 cells (Fig. 6B and C). Furthermore, LUCAT1 knockdown decreased the level of YAP1 mRNA and YAP1 overexpression abolished this effect (Fig. 6D). LUCAT1 silencing also suppressed YAP1 protein level, which was abolished by YAP1 overexpression (Fig. 6E and F). Therefore, the LUCAT1/miR-375/YAP1 regulatory axis may participate in the development of RCC. To further verify this hypothesis, CCK- 8 and Transwell experiments were performed. LUCAT1 knockdown suppressed the proliferation, migration and invasion of Caki-1 and A498 cells, which were reversed by the restoration of YAP1 expression (Fig. 6G-J). These results indicated that LUCAT1 knockdown suppressed RCC phenotypes via the miR-375/YAP1 regulatory axis. 
A
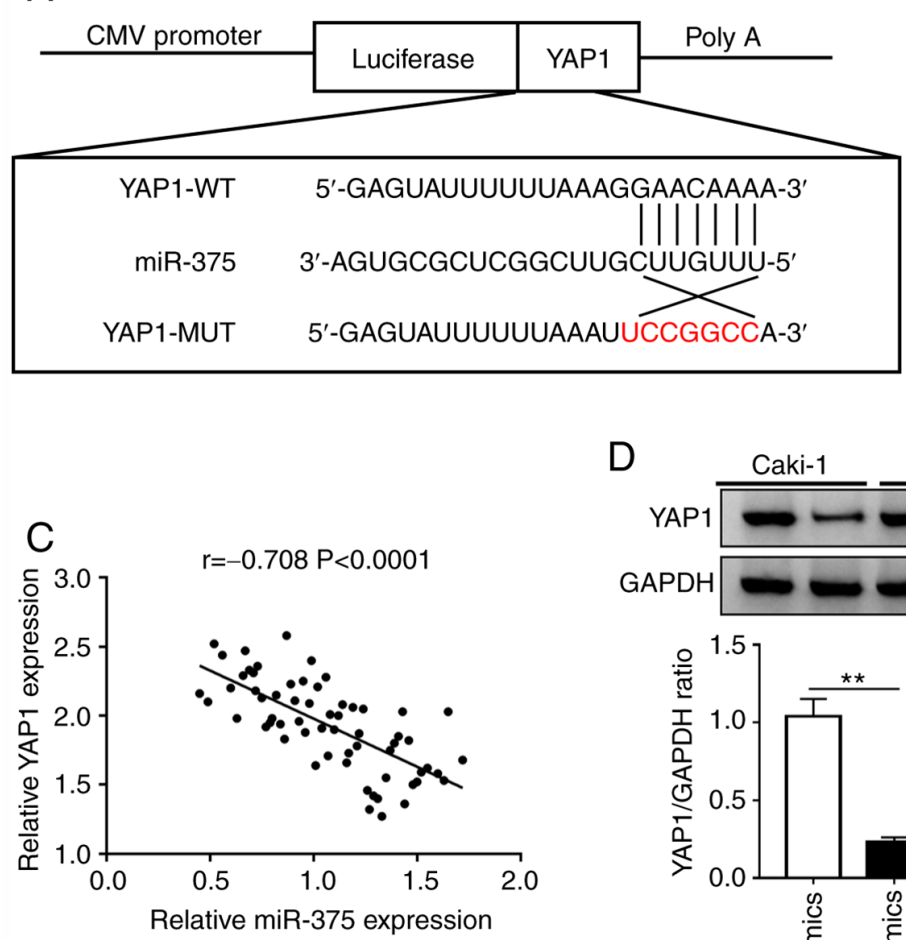

B

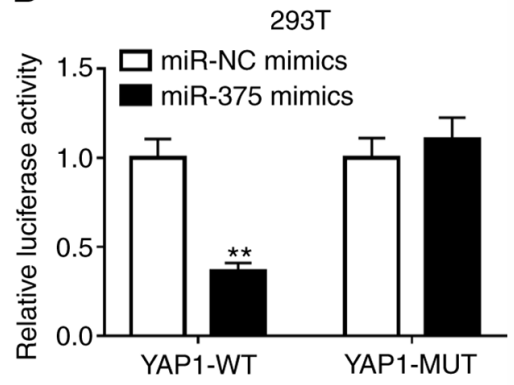

E
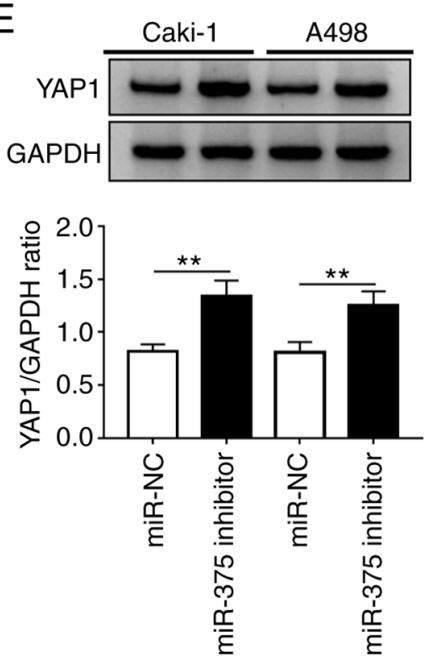

Figure 4. YAP1 is a direct target of miR-375 in RCC cells. (A) Predicted binding sites between miR-375 and YAP1-WT or MUT sites in YAP1-MUT reporter. (B) The effects of miR-375 overexpression on the luciferase activity of YAP1-WT or YAP1-MUT reporter were determined using a dual-luciferase reporter assay. (C) Pearson's correlation analysis was performed to assess the correlation between miR-375 and YAP1 expression levels in clear cell RCC tissues. The effects of miR-375 (D) overexpression or (E) knockdown on YAP1 protein expression were examined using western blot assay in Caki-1 and A498 cells. ${ }^{* *} \mathrm{P}<0.01$. YAP1, yes-associated protein 1; RCC, renal cell carcinoma; miR, microRNA; WT, wild-type; MUT, mutant; NC, negative control.

LUCAT1 deficiency suppresses ccRCC tumor growth in vivo. A xenograft tumor mouse model of ccRCC was used to verify the effect of LUCAT1 on tumor growth in vivo. Compared with the mice injected with sh-NC, tumor volume and weight were reduced in the sh-LUCAT1 group, indicating that LUCAT1 knockdown decreased the tumor growth of ccRCC in vivo (Fig. 7A-C). Additionally, RT-qPCR results verified that LUCAT1 was downregulated in the tumors of mice injected with sh-LUCAT1-transfected ccRCC Caki-1 cells (Fig. 7D). Taken together, these data suggested that LUCAT1 silencing suppressed ccRCC tumor growth in vivo.

\section{Discussion}

Accumulating evidence has suggested that lncRNAs emerged as essential regulators in tumorigenesis and potential biomarkers for the diagnosis or prognosis of ccRCC (22). LUCAT1 is located on chromosome 5q14.3, and was first identified in airway epithelial cells (23). It has been demonstrated that LUCAT1 was upregulated in ccRCC tissues and promoted the proliferation and invasion of ccRCC cells (10). However, the potential role and the regulatory mechanism of LUCAT1 in ccRCC progression requires further elucidation. YAP1, a transcriptional co-activator, has been indicated to promote tumorigenesis in various types of cancer, including ccRCC $(18,19)$.

In the present study, LUCAT1 and YAP1 were markedly upregulated in ccRCC tissues and cell lines. LUCAT1 expression was positively correlated with that of YAP1 in ccRCC tissues. In addition, LUCAT1 expression was closely associated with tumor stage, tumor size and lymph node metastasis in patients with ccRCC. Moreover, Kaplan-Meier survival curves suggested a negative association between high LUCAT1 expression and the overall survival of patients with ccRCC.

An interaction between IncRNAs and miRNAs has been identified in various cancers, such as bladder cancer, gastric cancer and ccRCC $(11,24,25)$. In the present study, miR-375 was revealed to be a direct target of LUCAT1. miR-375 has been reported to be a tumor suppressor in various types of cancer, including gastric cancer, glioma and ccRCC (14-17). For example, Wang and Sun (17) reported that miR-375 inhibited cell proliferation, migration and invasion via regulating 3-phosphoinositide-dependent protein kinase 1 expression in renal cancer. Consistent with a previously published study (17), the results of the present study indicated that miR-375 was significantly downregulated in ccRCC tissues and cell lines compared with healthy tissues and normal cells, respectively, and miR-375 expression level was 


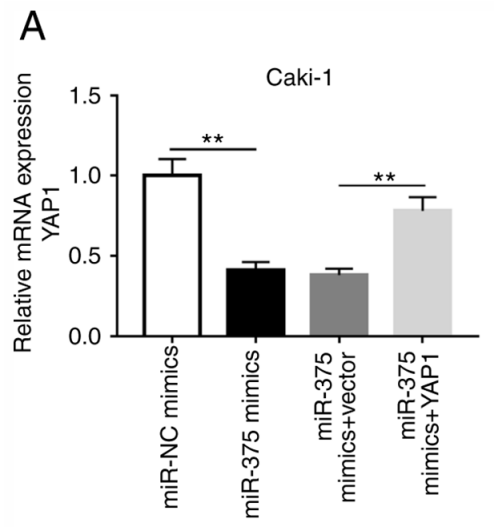

B

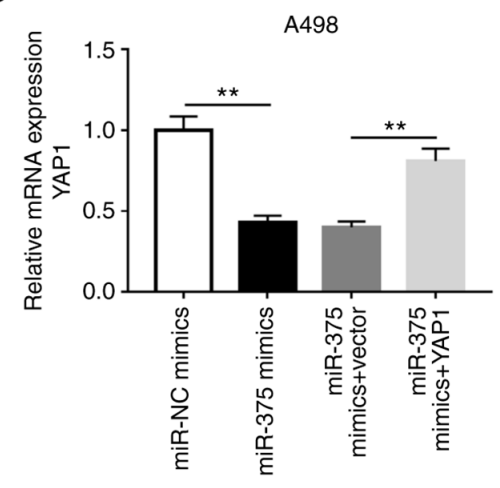

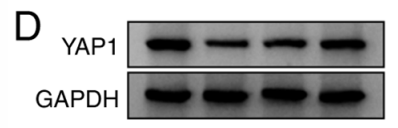

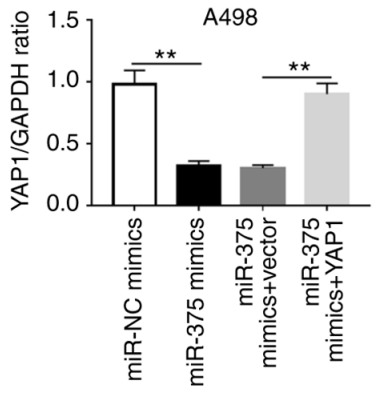

G
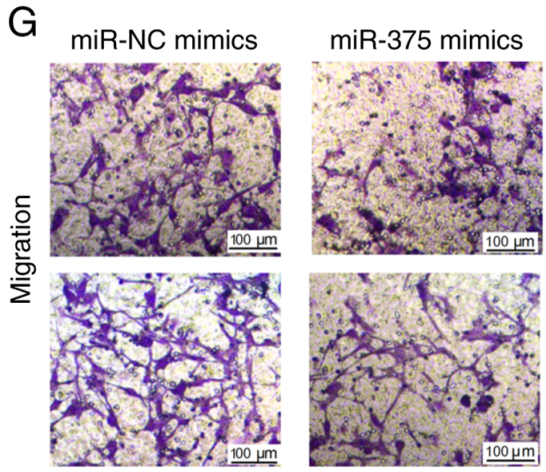

$\mathrm{H}$
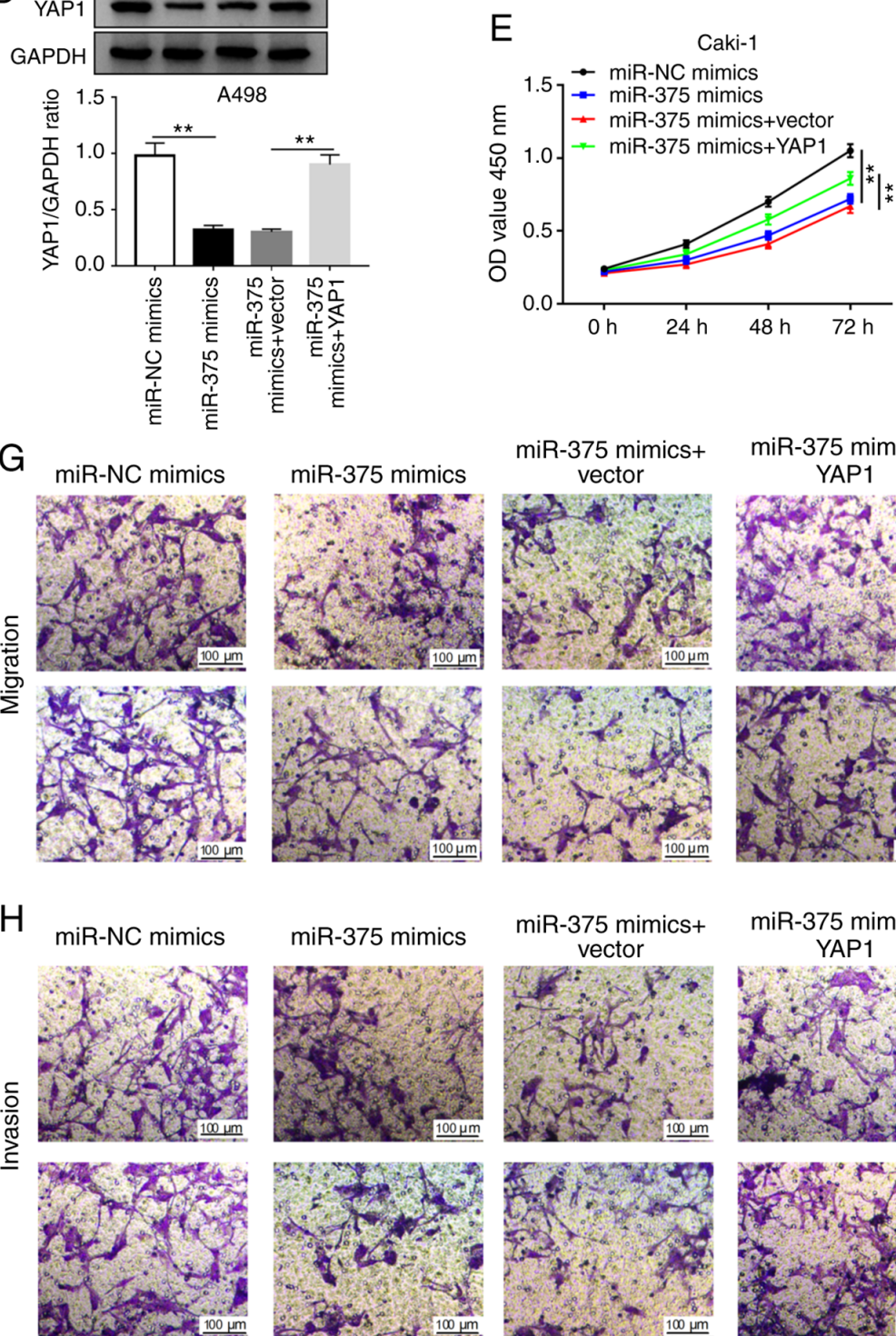

miR-375 mimics+ miR-375 mimics+ vector YAP1

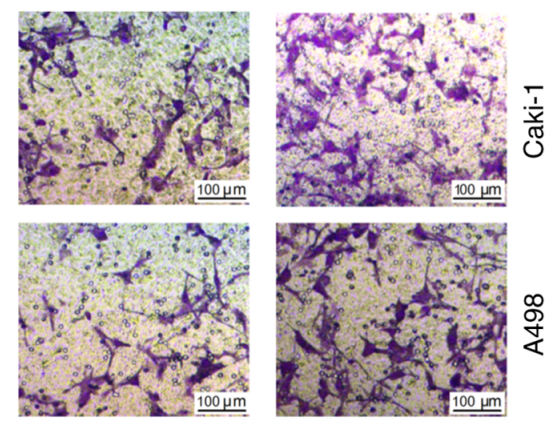

C
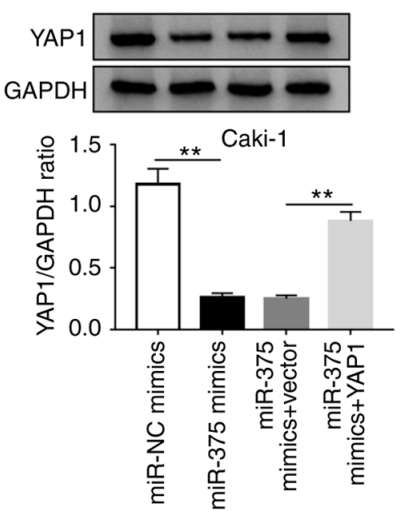

F
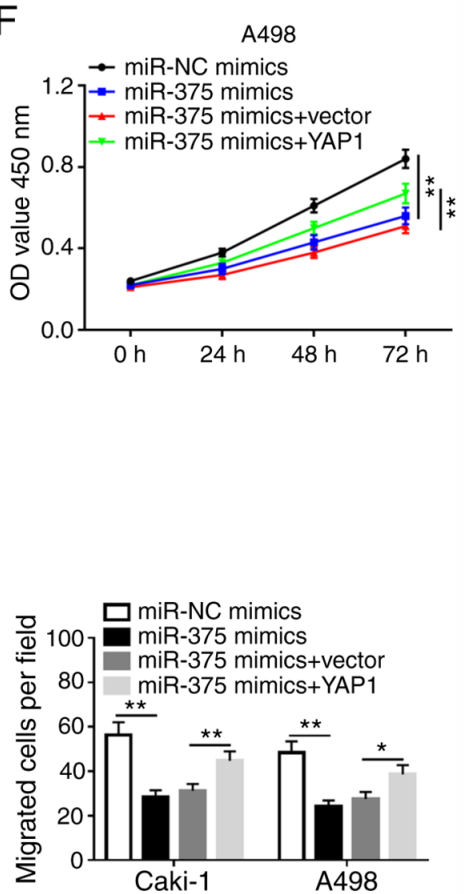

Figure 5. miR-375 suppresses the progression of renal cell carcinoma cells by targeting YAP1. YAP1 mRNA expression was determined by reverse transcription-quantitative PCR in (A) Caki-1 and (B) A498 cells transfected with miR-NC mimics, miR-375 mimics, miR-375 mimics+vector or miR-375 mimics+YAP1. YAP1 protein expression was detected by western blot in (C) Caki-1 and (D) A498 cells transfected with miR-NC mimics, miR-375 mimics, miR-375 mimics+vector or miR-375 mimics+YAP1. Cell proliferation was assessed using the Cell Counting Kit-8 assay in transfected (E) Caki-1 and (F) A498 cells. (G) Cell migratory and $(\mathrm{H})$ invasive capabilities were assessed via Transwell assay in transfected Caki-1 and A498 cells. ${ }^{*} \mathrm{P}<0.05$ and ${ }^{* *} \mathrm{P}<0.01$. YAP1, yes-associated protein 1; miR, microRNA; NC, negative control; OD, optical density.

negatively correlated with that of LUCAT1 in ccRCC tissues. Furthermore, it was observed that LUCAT1 suppressed the expression of miR-375 and promoted cell proliferation, migration and invasion by targeting miR-375. Moreover, the tumor-suppressive role of LUCAT1 knockdown in ccRCC was verified in vivo. 

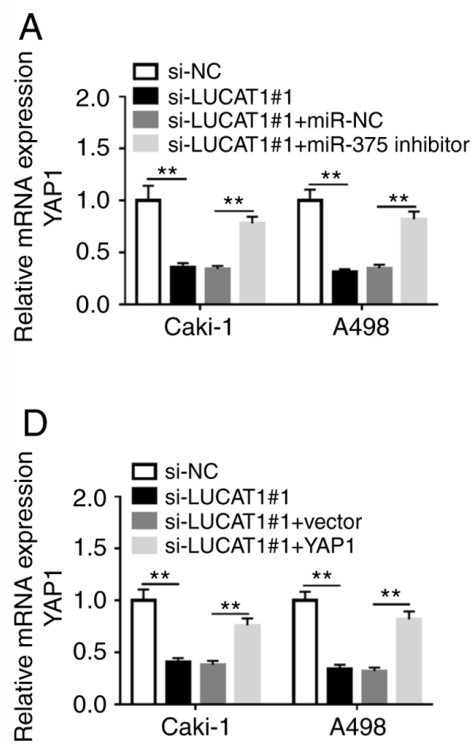
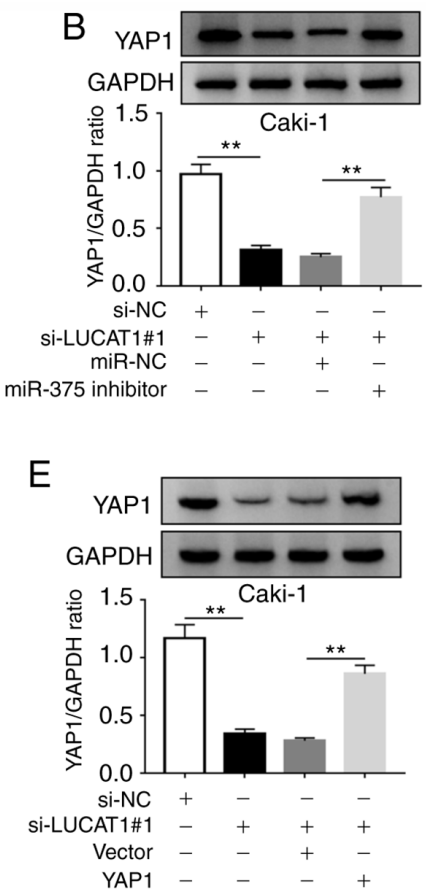
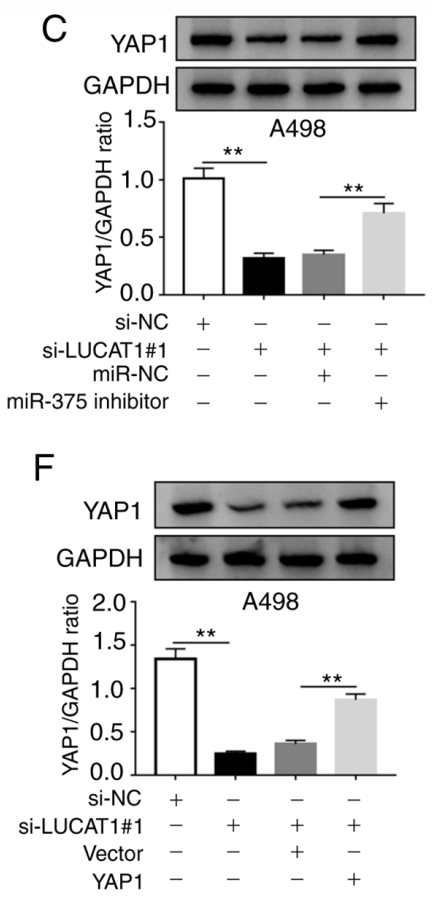
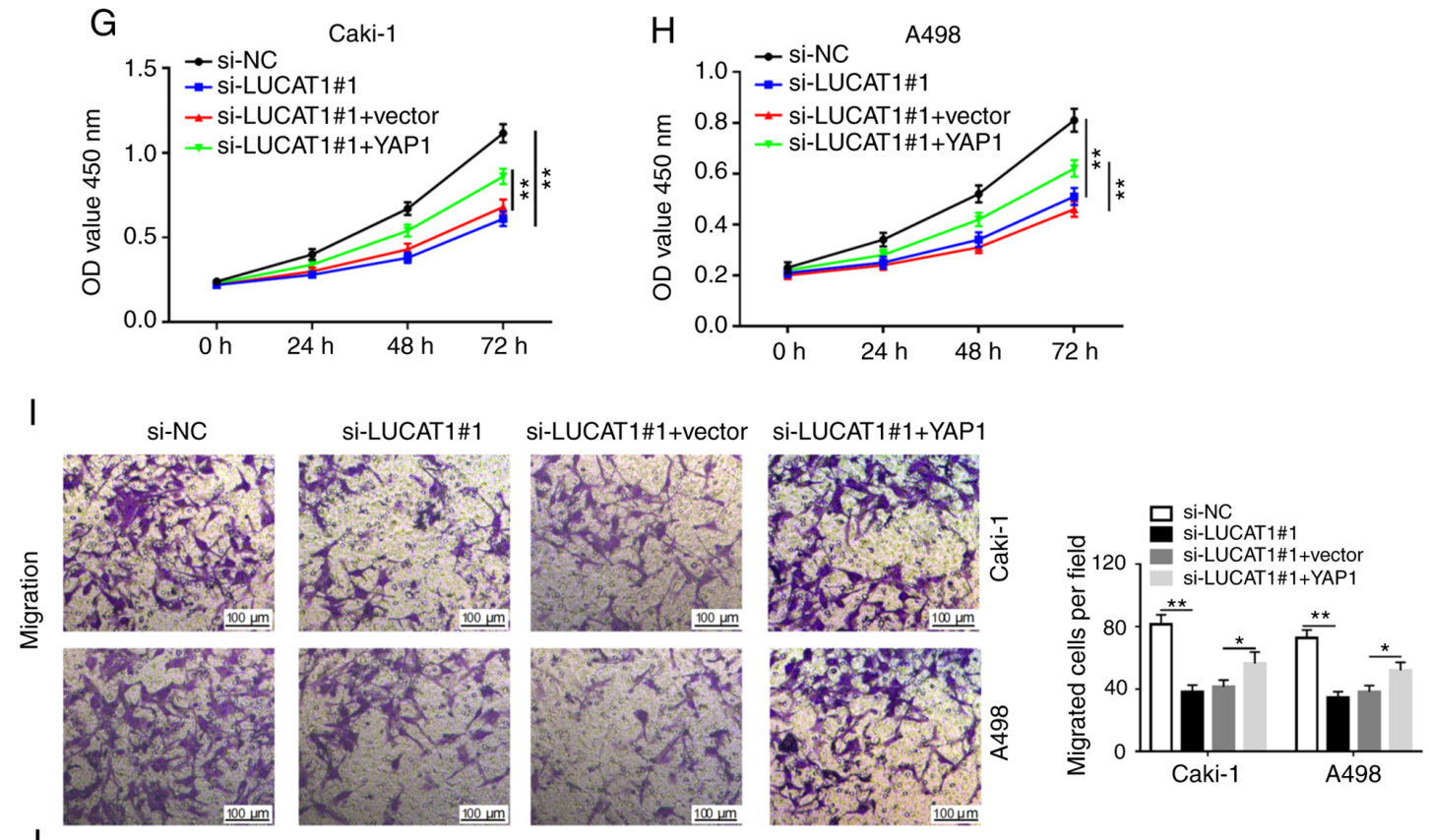

$\mathrm{J}$

Si-NC

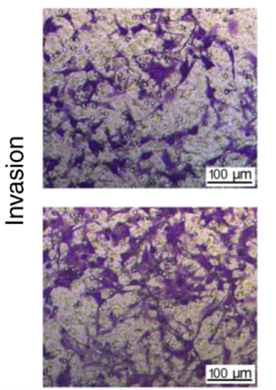

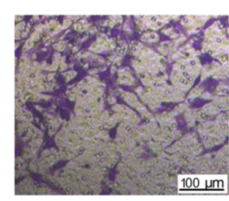

Si-LUCAT1\#1
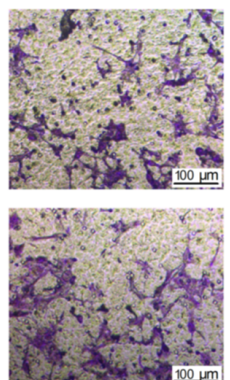

si-LUCAT1\#1+vector
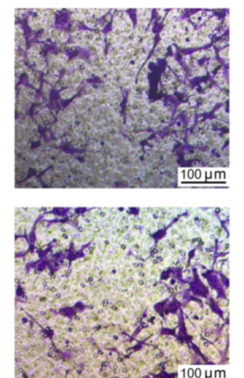

si-LUCAT1\#1+YAP1
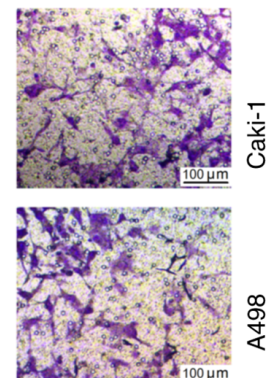

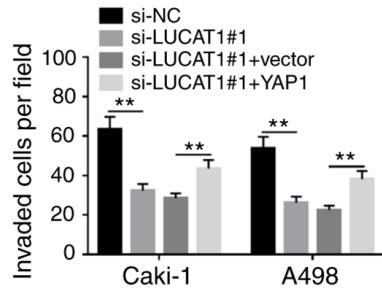

Figure 6. LUCAT1 enhances the proliferation, migration and invasion of renal cell carcinoma cells by targeting miR-375 to regulate YAP1 in vitro. (A) YAP1 mRNA expression was assessed by RT-qPCR in Caki-1 and A498 cells transfected with si-NC, si-LUCAT1\#1, si-LUCAT1\#1+miR-NC or si-LUCAT1\#1+miR-375 inhibitor. YAP1 protein expression was examined by western blotting in (B) Caki-1 and (C) A498 cells transfected si-NC, si-LUCAT1\#1, si-LUCAT1\#1+miR-NC or si-LUCAT1\#1+miR-375 inhibitor.(D) YAP1 mRNA level was assessed by RT-qPCR in Caki-1 and A498 cells transfected with si-NC, si-LUCAT1\#1, si-LUCAT1\#1+vector or si-LUCAT1\#1+YAP1. YAP1 protein level was examined by western blotting in (E) Caki-1 and (F) A498 cells transfected si-NC, si-LUCAT1\#1, si-LUCAT1\#1+vector or si-LUCAT1\#1+YAP1. Cell proliferation was measured using Cell Counting Kit-8 assay in transfected (G) Caki-1 and (H) A498 cells. (I) Cell migratory and (J) invasive capabilities were assessed by Transwell assay in transfected Caki-1 and A498 cells. ${ }^{*} \mathrm{P}<0.05$; ${ }^{* *} \mathrm{P}<0.01$. LUCAT1, lung cancer-associated transcript 1 ; YAP1, yes-associated protein 1; miR, microRNA; NC, negative control; si, small interfering; RT-qPCR, reverse transcription-quantitative PCR; OD, optical density. 


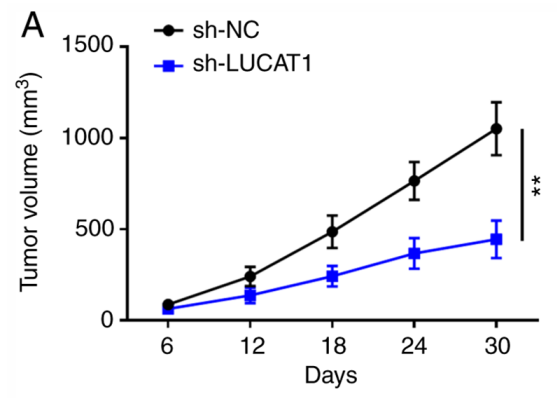

C

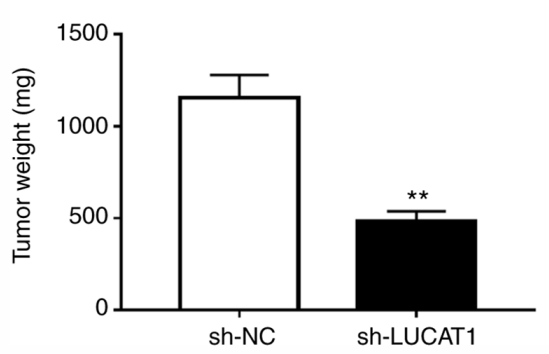

$\mathrm{B}$

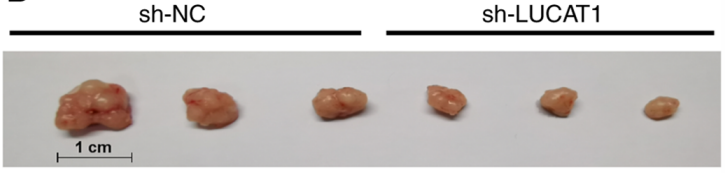

D

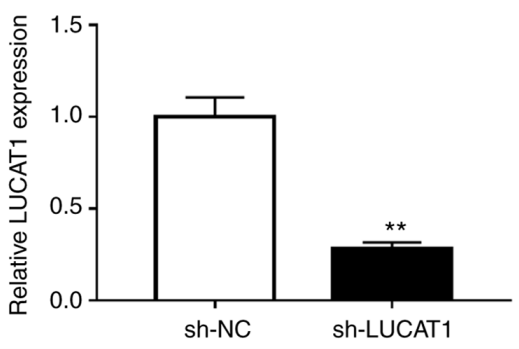

Figure 7. LUCAT1 knockdown suppresses clear cell renal cell carcinoma growth in vivo. (A) Tumor volume. (B) Images of tumors derived from Caki-1 cells stably transfected with sh-LUCAT1 or sh-NC. (C) Tumor weight. (D) The expression level of LUCAT1 was examined by reverse transcription-quantitative PCR. ${ }^{* *} \mathrm{P}<0.01$. LUCAT1, lung cancer-associated transcript 1; sh, short hairpin, NC, negative control.

It has been hypothesized that lncRNAs served as ceRNAs or miRNA sponges, regulating the expression of target mRNAs (26). Previous studies have demonstrated that miR-375 was associated with the progression of human cancers by regulating the expression of its target genes, such as SP1, PI3K-subunit $\alpha$ and HER2 (27-29). In the present study, YAP1 was revealed to be a target of miR-375 in RCC cells and was negatively regulated by miR-375. YAP1 has been indicated to be closely associated with cell proliferation, invasion and migration in prostate and colorectal cancer $(30,31)$. YAP1 overexpression reversed the inhibitory effects of miR-375 on the proliferation, migration and invasion of RCC cells, suggesting that miR-375 inhibited tumor progression by targeting YAP1. These data were consistent with previous studies in ovarian cancer (32), gastric carcinogenesis (14) and osteosarcoma (33). In addition, the results of the current study demonstrated that LUCAT1 may regulate YAP1 expression by sponging miR-375. Overexpression of YAP1 abolished the inhibitory effects of LUCAT1 knockdown on cell proliferation, invasion and migration in RCC cells, supporting the regulatory role of the LUCAT1/miR-375/YAP1 axis in RCC progression. However, due to the limited experimental conditions, the lack of immunofluorescence experiments was a limitation to the present study.

In conclusion, the present study indicated that LUCAT1 functioned as a sponge for miR-375 to upregulate YAP1 expression, thereby regulating the development of ccRCC. Our results revealed that LUCAT1 silencing suppressed the growth of ccRCC in vivo and in vitro. The present study also revealed that the LUCAT1/miR-375/YAP1 axis may be a promising therapeutic target for patients with ccRCC.

\section{Acknowledgements}

Not applicable.

\section{Funding}

No funding was received.

\section{Availability of data and materials}

The datasets used and/or analyzed during the current study are available from the corresponding author on reasonable request.

\section{Authors' contributions}

$\mathrm{XW}$ conceived and designed the study and prepared the first draft of the manuscript. XW, HO, LZ, HL, HZ and XL performed the experiments, reviewed and agreed to the final submission of the manuscript. HO, LZ, HL, HZ and XL analyzed and interpreted the data. XW and HO confirm the authenticity of the raw data. All authors read and approved the final manuscript.

\section{Ethics approval and consent to participate}

The human study was approved by the Ethics Committee of Chenzhou No. 1 People's Hospital (Chenzhou, China) and all participants provided written informed consent. The animal study was approved by the Animal Ethics Committee of Chenzhou No. 1 People's Hospital.

\section{Patient consent for publication}

Not applicable.

\section{Competing interests}

The authors declare that they have no competing interests. 


\section{References}

1. Moch H, Cubilla AL, Humphrey PA, Reuter VE and Ulbright TM: The 2016 WHO classification of tumours of the urinary system and male genital organs-part A: Renal, penile, and testicular tumours. Eur Urol 70: 93-105, 2016.

2. Ricketts CJ, De Cubas AA, Fan H, Smith CC, Lang M, Reznik E, Bowlby R, Gibb EA, Akbani R, Beroukhim R, et al: The cancer genome atlas comprehensive molecular characterization of renal cell carcinoma. Cell Rep 23: 313-326.e5, 2018.

3. Keegan KA, Schupp CW, Chamie K, Hellenthal NJ, Evans CP and Koppie TM: Histopathology of surgically treated renal cell carcinoma: Survival differences by subtype and stage. J Urol 188: 391-397, 2012.

4. Wang L and Lee BR: Novel agents and approaches for advanced renal cell carcinoma. J Urol 188: 716, 2012.

5. Capitanio U and Montorsi F: Renal cancer. Lancet 387: 894-906, 2016.

6. Wu R, Su Y, Wu H, Dai Y, Zhao M and Lu Q: Characters, functions and clinical perspectives of long non-coding RNAs. Mol Genet Genomics 291: 1013-1033, 2016.

7. Liu G, Zhao X, Zhou J, Cheng X, Ye Z and Ji Z: lncRNA TP73-AS1 promotes cell proliferation and inhibits cell apoptosis in clear cell renal cell carcinoma through repressing KISS1 expression and inactivation of $\mathrm{PI} 3 \mathrm{~K} / \mathrm{Akt} / \mathrm{mTOR}$ signaling pathway. Cell Physiol Biochem 48: 371-384, 2018.

8. Hirata H, Hinoda Y, Shahryari V, Deng G, Nakajima K, Tabatabai ZL, Ishii N and Dahiya R: Long noncoding RNA MALAT1 promotes aggressive renal cell carcinoma through Ezh2 and interacts with miR-205. Cancer Res 75: 1322-1331, 2015.

9. Xiao H, Bao L, Xiao W, Ruan H, Song Z, Qu Y, Chen K, Zhang X and Yang H: Long non-coding RNA Lucatl is a poor prognostic factor and demonstrates malignant biological behavior in clear cell renal cell carcinoma. Oncotarget 8: 113622-113634, 2017.

10. Zheng Z, Zhao F, Zhu D, Han J, Chen H, Cai Y, Chen Z and Xie W: Long non-coding RNA LUCAT1 promotes proliferation and invasion in clear cell renal cell carcinoma through AKT/GSK-3 $\beta$ signaling pathway. Cell Physiol Biochem 48: 891-904, 2018.

11. Wang LN, Zhu XQ, Song XS and Xu Y: Long noncoding RNA lung cancer associated transcript 1 promotes proliferation and invasion of clear cell renal cell carcinoma cells by negatively regulating miR-495-3p. J Cell Biochem 119: 7599-7609, 2018.

12. Bartel DP: Metazoan microRNAs. Cell 173: 20-51, 2018.

13. He YH, Chen $\mathrm{C}$ and Shi Z: The biological roles and clinical implications of microRNAs in clear cell renal cell carcinoma. J Cell Physiol 233: 4458-4465, 2018.

14. Kang W, Huang T, Zhou Y, Zhang J, Lung RWM, Tong JHM, Chan AWH, Zhang B, Wong CC, Wu F, et al: miR-375 is involved in Hippo pathway by targeting YAP1/TEAD4-CTGF axis in gastric carcinogenesis. Cell Death Dis 9: 92, 2018.

15. Ji CX, Fan YH, Xu F, Lv SG, Ye MH, Wu MJ, Zhu XG and Wu L: MicroRNA-375 inhibits glioma cell proliferation and migration by downregulating RWDD3 in vitro. Oncol Rep 39: 1825-1834, 2018.

16. Liu S, Song L, Yao H, Zhang L, Xu D, Gao F and Li Q: miR-375 Is epigenetically downregulated by HPV-16 E6 mediated DNMT1 upregulation and modulates EMT of cervical cancer cells by suppressing lncRNA MALAT1. PLoS One 11: e0163460, 2016.

17. Wang J and Sun X: MicroRNA-375 inhibits the proliferation, migration and invasion of kidney cancer cells by triggering apoptosis and modulation of PDK1 expression. Environ Toxicol Pharmacol 62: 227-233, 2018.
18. Rybarczyk A, Klacz J, Wronska A, Matuszewski M, Kmiec Z and Wierzbicki PM: Overexpression of the YAP1 oncogene in clear cell renal cell carcinoma is associated with poor outcome. Oncol Rep 38: 427-439, 2017

19. Xiao J, Shi Q, Li W, Mu X, Peng J, Li M, Chen M, Huang H, Wang C, Gao K and Fan J: ARRDC1 and ARRDC3 act as tumor suppressors in renal cell carcinoma by facilitating YAP1 degradation. Am J Cancer Res 8: 132-143, 2018.

20. Livak KJ and Schmittgen TD: Analysis of relative gene expression data using real-time quantitative PCR and the 2(-Delta Delta C(T)) method. Methods 25: 402-408, 2001.

21. Karreth FA and Pandolfi PP: ceRNA cross-talk in cancer: When ce-bling rivalries go awry. Cancer Discov 3: 1113-1121, 2013.

22. Gayed BA, Youssef RF, Bagrodia A, Kapur P, Darwish OM, Krabbe LM, Sagalowsky A, Lotan Y and Margulis V: Prognostic role of cell cycle and proliferative biomarkers in patients with clear cell renal cell carcinoma. J Urol 190: 1662-1667, 2013.

23. Thai P, Statt S, Chen CH, Liang E, Campbell C and Wu R: Characterization of a novel long noncoding RNA, SCAL1, induced by cigarette smoke and elevated in lung cancer cell lines. Am J Respir Cell Mol Biol 49: 204-211, 2013.

24. Wieczorek E and Reszka E: MRNA, microRNA and lncRNA as novel bladder tumor markers. Clin Chim Acta 477: 141-153, 2018.

25. Zhang G, Li S, Lu J, Ge Y, Wang Q, Ma G, Zhao Q, Wu D, Gong W, Du M, et al: lncRNA MT1JP functions as a ceRNA in regulating FBXW7 through competitively binding to miR-92a-3p in gastric cancer. Mol Cancer 17: 87, 2018.

26. Salmena L, Poliseno L, Tay Y, Kats L and Pandolfi PP: A ceRNA hypothesis: The Rosetta Stone of a hidden RNA language? Cell 146: 353-358, 2011.

27. Liu XH, Wang J and Dong YH: The inhibitory effect of miR-375 targeting sp1 in colorectal cancer cell proliferation. Eur Rev Med Pharmacol Sci 22: 405-411, 2018.

28. Wang Y, Tang Q, Li M, Jiang S and Wang X: MicroRNA-375 inhibits colorectal cancer growth by targeting PIK3CA. Biochem Biophys Res Commun 444: 199-204, 2014.

29. Cheng L, Zhan B, Luo P and Wang B: miRNA375 regulates the cell survival and apoptosis of human non-small cell carcinoma by targeting HER2. Mol Med Rep 15: 1387-1392, 2017.

30. Shi Y, Cao T, Sun Y, Xia J, Wang P and Ma J: Nitidine Chloride inhibits cell proliferation and invasion via downregulation of YAP expression in prostate cancer cells. Am J Transl Res 11: 709-720, 2019.

31. Zhou Z, Zhang HS, Zhang ZG, Sun HL, Liu HY, Gou XM, Yu XY and Huang YH: Loss of HACE1 promotes colorectal cancer cell migration via upregulation of YAP1. J Cell Physiol 234: 9663-9672, 2019.

32. Yan H, Li H, Li P, Li X, Lin J, Zhu L, Silva MA, Wang X, Wang P and Zhang Z: Long noncoding RNA MLK7-AS1 promotes ovarian cancer cells progression by modulating miR-375/YAP1 axis. J Exp Clin Cancer Res 37: 237, 2018.

33. Liu G, Huang K, Jie Z, Wu Y, Chen J, Chen Z, Fang X and Shen S: CircFAT1 sponges miR-375 to promote the expression of Yes-associated protein 1 in osteosarcoma cells. Mol Cancer 17: 170,2018

This work is licensed under a Creative Commons Attribution-NonCommercial-NoDerivatives 4.0 International (CC BY-NC-ND 4.0) License. 